\title{
Survey of Clostridium difficile infection surveillance systems in Europe, 2011
}

A Kola ${ }^{1}$, C Wiuff ${ }^{2}$, T Akerlund ${ }^{3}$, BH van Benthem ${ }^{4}$, B Coignard 5 , 0 Lyytikäinen ${ }^{6}$, D Weitzel-Kage ${ }^{1}$, C Suetens ${ }^{7}$, MH Wilcox ${ }^{8} 9$ , EJ Kuijper ${ }^{10}$, P Gastmeier ${ }^{1}$, on behalf of members of ECDIS-Net ${ }^{11}$

1. Charité - Universitätsmedizin Berlin, Germany

2. Health Protection Scotland, Glasgow, United Kingdom

3. Swedish National Institute of Public Health, Solna, Sweden

4. Center for Infectious Diseases Control, National Institute for Public Health and the Environment (RIVM), Bilthoven, the Netherlands

5. Institut de Veille Sanitaire, Saint-Maurice Cedex, France

6. National Institute for Health and Welfare, Helsinki, Finland

7. European Centre for Disease Prevention and Control (ECDC), Stockholm, Sweden

8. Leeds Teaching Hospitals NHS Trust, Leeds, United Kingdom

9. University of Leeds, Leeds, United Kingdom

10. Leiden University Medical Center, Leiden, the Netherlands

11. The members of ECDIS-Net are listed at the end of the articl

Correspondence: Axel Kola (axel.kola@charite.de)

Citation style for this article:

Kola A, Wiuff C, Akerlund T, van Benthem BH, Coignard B, Lyytikäinen O, Weitzel-Kage D, Suetens C, Wilcox MH, Kuijper EJ, Gastmeier P, on behalf of members of ECDIS-Net. Survey of Clostridium difficile infection surveillance systems in Europe, 2011. Euro Surveill. 2016;21(29):pii=30291. D0I: http://dx.doi.

org/10.2807/1560-7917.ES.2016.21.29.30291

Article submitted on 05 February 2016 / accepted on 03 June 2016 / published on 21 July 2016

To develop a European surveillance protocol for Clostridium difficile infection (CDI), existing national CDI surveillance systems were assessed in 2011. A web-based electronic form was provided for all national coordinators of the European CDI Surveillance Network (ECDIS-Net). Of 35 national coordinators approached, 33 from 31 European countries replied. Surveillance of CDI was in place in 14 of the 31 countries, comprising 18 different nationwide systems. Three of 14 countries with CDI surveillance used public health notification of cases as the route of reporting, and in another three, reporting was limited to public health notification of cases of severe CDI. The CDI definitions published by the European Society of Clinical Microbiology and Infectious Diseases (ESCMID) and the European Centre for Disease Prevention and Control (ECDC) were widely used, but there were differing definitions to distinguish between communityand healthcare-associated cases. All CDI surveillance systems except one reported annual national CDI rates (calculated as number of cases per patient-days). Only four surveillance systems regularly integrated microbiological data (typing and susceptibility testing results). Surveillance methods varied considerably between countries, which emphasises the need for a harmonised European protocol to allow consistent monitoring of the CDI epidemiology at European level. The results of this survey were used to develop a harmonised EU-wide hospital-based CDI surveillance protocol.

\section{Introduction}

Since 2000 , a considerable increase in the number of Clostridium difficile infections (CDIs) leading to substantial morbidity, mortality and attributable costs has been observed, at least in North America and Europe [1]. Changes in the epidemiology of CDI have been mainly attributed to the emergence of a new hypervirulent strain called PCR ribotype 027 , causing numerous outbreaks in North America and Europe [2,3] and, to a lesser extent, PCR ribotype $078[1,4,5]$. In addition, patients not previously considered to be at risk for the disease (e.g., without recent antibiotic therapy or hospitalisation) have also been described [1,6-8]. The European CDI study (ECDIS), initiated and funded by the European Centre for Disease Prevention and Control (ECDC), showed that the incidence of CDI varied from hospital to hospital [9]. In 2008, a weighted mean incidence of 4.1 cases (range: $0.0-36.3$ ) per 10,000 patient-days per hospital reported by the ECDIS study was almost $70 \%$ higher than that reported in a previous European surveillance study in 2005 (2.45 cases per 10,000 patient-days per hospital, range: 0.13-7.1) $[9,10]$. ECDIS also revealed the contribution of strains other than PCR ribotype 027 and that some of these strains, notably PCR ribotypes 015, 018 and 056, could cause severe CDI.

In response to the emerging problems associated with C. difficile, an ECDC working group published background information about the changing epidemiology of CDI, CDI case definitions and surveillance recommendations [2]. To support European Union (EU)/European 
TABLE

Characteristics of European Clostridium difficile infection surveillance systems, 2011 (18 surveillance systems from 14 countries)

\begin{tabular}{|c|c|c|c|c|c|}
\hline Country & Name & Participants & $\begin{array}{l}\text { General } \\
\text { remarks }\end{array}$ & Epidemiological data & Microbiological data \\
\hline Austria & No name & All $H / L / G$ & $\begin{array}{c}M \\
C+P \\
L b+C b \\
\text { only sevCDI }\end{array}$ & $\begin{array}{l}\text { Total number } \\
\text { CDI-days }\end{array}$ & $\begin{array}{l}\text { RTcp } \\
\text { AST }\end{array}$ \\
\hline Belgium & $\begin{array}{c}\text { National Surveillance of Infections in } \\
\text { Hospitals (NSIH) }\end{array}$ & $110 \mathrm{H}$ & $\begin{array}{c}\mathrm{M} \\
\mathrm{P} \\
\mathrm{Cb} \\
\text { Periodic } \\
\text { (6 months a year) }\end{array}$ & $\begin{array}{c}\text { HA-CDI: } \\
\text { I ( } 1,000 \mathrm{pa} / 6 \text { months }) \\
\text { Id (10,000 pd/6 months) } \\
\text { Severe CDI: } \\
\text { ICU-adm/death within } \\
\text { 30 days related to CDI }\end{array}$ & $\begin{array}{l}\text { TcdT (fp/sevCDI /ob) } \\
\text { AST (fp/sevCDI /ob) }\end{array}$ \\
\hline Bulgaria & BGCDISS & $6 \mathrm{H} / 3 \mathrm{~L}$ & $\begin{array}{c}V \\
C+P \\
L b+C b\end{array}$ & $\begin{array}{c}\text { HA-CDI: } \\
\text { I (10,000 pa) } \\
\text { Id (10,000 pd })\end{array}$ & $\begin{array}{l}\text { RTcp } \\
\text { No AST }\end{array}$ \\
\hline Denmark & $\begin{array}{l}\text { Surveillance of epidemic } \\
\text { hypervirulent CD in Denmark }\end{array}$ & $13 \mathrm{H} / 13 \mathrm{~L}$ & $\begin{array}{c}\mathrm{V} \\
\mathrm{C}+\mathrm{P} \\
\mathrm{Lb}\end{array}$ & I (number of episodes/region) & $\begin{array}{c}\text { RTag }(\operatorname{sev} C D I+\text { MoxR }) / o b) \\
\text { AST }\end{array}$ \\
\hline Finland-1 & National Infectious Diseases Register & All L & $\begin{array}{c}M \\
C+P \\
L b\end{array}$ & I (100,000 inh) & $\begin{array}{l}\text { RTag (sevCDI/ob) } \\
\text { No AST }\end{array}$ \\
\hline Finland-2 & $\begin{array}{l}\text { Finnish Hospital Infection Programme } \\
\text { (SIRO) }\end{array}$ & $12 \mathrm{H}$ & $\begin{array}{l}V \\
C+P \\
C b\end{array}$ & $\begin{array}{c}\text { HA-CDI: } \\
\text { I (100 pa) } \\
\text { Id (1000 pd) } \\
\text { Severe CDI: } \\
\text { ICU-adm/surgery/ death within } 30 \\
\text { days related to CDI }\end{array}$ & None \\
\hline Finland-3 & $\begin{array}{l}\text { National Hospital Discharge Register } \\
\text { (HILMO) }\end{array}$ & $57 \mathrm{H}$ & $\begin{array}{c}M \\
\text { C(retrosp.) } \\
\text { ICD 10-based }\end{array}$ & $\begin{array}{l}\text { I (CDI hospitalisations/ } \\
100,000 \mathrm{inh})\end{array}$ & None \\
\hline France & $\begin{array}{l}\text { Healthcare acquired Infections Early } \\
\text { warning and Response system }\end{array}$ & $100 \mathrm{H} / 115 \mathrm{~L} / 10 \mathrm{~N}$ & $\begin{array}{c}M \\
C+P \\
C b \\
\text { only sevCDI/ob }\end{array}$ & $\begin{array}{l}\text { Severe CDI: } \\
\text { Total number } \\
\text { I ( }(1,000 \mathrm{pa}) \\
\text { Id }(10,000 \mathrm{pd})\end{array}$ & $\begin{array}{l}\text { RTag (sevCDI/ob) } \\
\text { AST (sevCDI/ob) }\end{array}$ \\
\hline Germany-1 & CDAD-KISS & $126 \mathrm{H}$ & $\begin{array}{l}\mathrm{V} \\
\mathrm{C}+\mathrm{P} \\
\mathrm{Cb}\end{array}$ & $\begin{array}{l}\text { HA-CDI/severe CDI: } \\
\text { I (100 adm) } \\
\text { Id }(1,000 \mathrm{pd})\end{array}$ & None \\
\hline Germany-2 & SurvNet & About $2000 \mathrm{H}$ & $\begin{array}{c}M \\
\mathrm{C}+\mathrm{P} \\
\mathrm{Cb} \\
\text { only sevCDI/ } \\
\text { ribotype } 027\end{array}$ & $\begin{array}{l}\text { Severe CDI: } \\
\text { Total number } \\
\text { I (100,000 inh/ } \\
\text { ICU-adm/surgery/ } \\
\text { death within } 30 \text { days } \\
\text { related to CDI) } \\
\end{array}$ & $\begin{array}{l}\text { RTcp (sevCDI/ob) } \\
\text { No AST }\end{array}$ \\
\hline Hungary & $\begin{array}{l}\text { Epidemiological Control System and } \\
\text { Information System (EFRIR) }\end{array}$ & $35 \mathrm{H} / 14 \mathrm{~L}$ & $\begin{array}{c}M \\
C+P \\
L b+C b\end{array}$ & Total number & $\begin{array}{l}\text { RTag (sevCDI/ob) } \\
\text { No AST }\end{array}$ \\
\hline Ireland-1 & Notifiable $C$. difficile Surveillance & $\begin{array}{l}48 \mathrm{H} / 37 \mathrm{~L} / \text { all } \\
\mathrm{G} \text { from } 8 \text { public } \\
\text { health regions }\end{array}$ & $\begin{array}{c}M \\
C+P \\
C b\end{array}$ & I (100,000 inh) & None \\
\hline Ireland-2 & C. difficile Enhanced Surveillance & $34 \mathrm{H} / 34 \mathrm{~L}$ & $\begin{array}{l}\mathrm{V} \\
\mathrm{C}+\mathrm{P} \\
\mathrm{Cb}\end{array}$ & $\begin{array}{c}\text { HA-CDI: } \\
\text { Id (10,000 pd) } \\
\text { Severe CDI: } \\
\text { ICU-adm/ } \\
\text { surgery related to CDI }\end{array}$ & None \\
\hline $\begin{array}{l}\text { The } \\
\text { Netherlands }\end{array}$ & Sentinel surveillance of $C$. difficile & $19 \mathrm{H} / 19 \mathrm{~L}$ & $\begin{array}{c}V \\
C+P \\
L b+C b\end{array}$ & $\begin{array}{c}\text { HA-CDI: } \\
\text { I (CDI cases/pa) } \\
\text { Id (CDI cases/pd) }\end{array}$ & $\begin{array}{l}\text { RTag (fp) } \\
\text { No AST }\end{array}$ \\
\hline Sweden & $\begin{array}{l}\text { National Laboratory-based CD } \\
\text { Surveillance System }\end{array}$ & $20 \mathrm{~L}$ & $\begin{array}{c}\mathrm{V} \\
\mathrm{C}+\mathrm{P} \\
\mathrm{Lb}\end{array}$ & Total number & $\begin{array}{l}\text { RTac (fp/sevCDI /ob) } \\
\text { AST (fp) }\end{array}$ \\
\hline UK-England & HCAI Data Capture System & $\begin{array}{l}167 \text { NHS Acute } \\
\text { Trusts with } 1-2 \mathrm{H} \\
\text { each }\end{array}$ & $\begin{array}{c}M \\
C+P \\
L b\end{array}$ & $\begin{array}{c}\text { All types of CDI: } \\
\text { Id (adm > 65 y/1,000 pd) } \\
\text { HA-CDI: } \\
\text { Id (cases }>2 \text { y/10,000 pd) } \\
\text { Severe CDI: } \\
\text { Death within } 30 \text { days } \\
\text { related to CDI }\end{array}$ & $\begin{array}{c}\text { RTca } \\
\text { AST (fp) }\end{array}$ \\
\hline $\begin{array}{l}\text { UK-Northern } \\
\text { Ireland }\end{array}$ & $\begin{array}{l}\text { Enhanced HCAI Web-based } \\
\text { Surveillance System }\end{array}$ & $\begin{array}{l}28 \mathrm{H} / 5 \mathrm{~L} / 358 \mathrm{GP} / \\
240 \mathrm{~N} / 237 \mathrm{R}\end{array}$ & $\begin{array}{l}M \\
\mathrm{C}+\mathrm{P} \\
\mathrm{Lb}\end{array}$ & $\begin{array}{l}\text { HA-CDI and CA-CDI: } \\
\text { Total number } \\
\text { Id }(1,000 \mathrm{pd})\end{array}$ & RTcp/no AST \\
\hline UK-Scotland & $\begin{array}{c}\text { Scottish Mandatory Surveillance } \\
\text { Programme for CDI }\end{array}$ & $\begin{array}{l}23 \mathrm{~L} \text { and } 14 \mathrm{NHS} \\
\text { health boards } \\
\text { including } \mathrm{H} / \mathrm{N} / \mathrm{G}\end{array}$ & $\begin{array}{c}M \\
C+P \\
L b+C b\end{array}$ & $\begin{array}{c}\text { HA-CDI: } \\
\text { Id (cases } \geq 15 \text { y/1000 pd) }\end{array}$ & $\begin{array}{l}\text { RTag (fp/sevCDI/ob) } \\
\text { AST (fp/sevCDI/ob) }\end{array}$ \\
\hline
\end{tabular}

ac: acrylamide; adm: admissions; ag: agarose; AST: antimicrobial susceptibility testing; C: continuous; CA: community associated; $C P$ : $c$ apillary; Cb: case-based; CD; Clostridium difficile; CDI: Clostridium difficile infection; fp: fixed proportion; G: general practioners; $\mathrm{H}$ : hospitals; HA: healthcare associated; I: incidence; ICD-10: International Statistical Classification of Diseases 1oth revision; ICU: intensive-care unit; Id: incidence density; inh: inhabitants; L: laboratories; Lb: laboratory-based; M: mandatory; MoxR: moxifloxacin resistance; N: nursing homes; ob: outbreaks; pa: patient admissions; pd: patient-days; R: residential homes; retrosp.: retrospective; RT: ribotyping; sevCDI: severe CDI; TcdC: typing of the tcdC gene; UK: United Kingdom; V: voluntary; y: years.

${ }^{a}$ Iceland and UK-Wales did not reply to the web-based questionnaire.

${ }^{\mathrm{b}}$ Some countries had more than one surveillance system in parallel. Where relevant, they are shown with the suffixes $-1,-2$ and -3 . 
Economic Area (EEA) Member States in increasing their capacity for CDI surveillance, ECDC also initiated and funded a new project - ECDIS-Net - to develop a European surveillance protocol and enhance laboratory capacity for diagnosis and typing of $C$. difficile in EU/ EEA Member States.

In 2011, a survey of existing CDI surveillance systems in European countries was performed as part of the ECDIS-Net project. The results of this survey, presented here, were later used to develop a standardised pan-European CDI surveillance protocol, which was tested in a three-month pilot study in 2013 [11]. Data collection in the ECDC-coordinated Europe-wide hospital-based CDI surveillance, using a finalised version of this piloted protocol, began on 1 January 2016 [12].

\section{Methods}

National coordinators for this study were identified through the members of ECDC's Healthcare-Associated Infections surveillance Network (HAI-Net) and via representatives for the ECDIS study [9]. A link to a web-based questionnaire was sent to these national coordinators to assess the characteristics of existing CDI surveillance systems in European countries. If the national coordinators indicated that CDI was under surveillance in their country, the surveillance protocols were requested and used to augment the information obtained via the questionnaire. Information on the national CDI surveillance systems was entered using a web-based electronic form designed for the purpose of this study.

\section{Results}

Between 6 June and 15 July 2011, 33 of the 35 national coordinators approached from 31 European countries responded to the web-based questionnaire (Iceland and Wales did not respond). Four surveillance systems were excluded from further analysis, as they were not ongoing, comprehensive nationwide surveillance systems, i.e. they were completed one-off studies (two studies from Spain), only regional (Switzerland) or focused only on outbreaks (one system of the Netherlands). In 14 countries, the national coordinators indicated that surveillance of CDI was in place. Of these, surveillance protocols were available from 10 surveillance systems. Thus, $18 \mathrm{CDI}$ surveillance systems from 14 European countries (Austria, Belgium, Bulgaria, Denmark, Finland, France, Germany, Hungary, Ireland, the Netherlands, Sweden and three countries of the United Kingdom (UK), England, Northern Ireland and Scotland) remained available for analysis. Of the 18 surveillance systems, all but one reported national CDI rates annually.

\section{General characteristics of $C$. difficile infection surveillance systems}

An overview of the European CDI surveillance systems is given in the Table. In summary, 11/18 surveillance systems used mandatory reporting and seven used voluntary reporting of cases. The majority (16/18) of the surveillance systems were continuous and prospective, one was periodical and prospective (Belgium), and one was retrospective (Finland-3). In three countries (Germany, Ireland, the Netherlands), two surveillance systems were run in parallel, (shown with the suffixes -1 and -2). In Finland, there were three parallel systems (Finland-1, -2 and -3). Parallel systems were also in place in the three parts of the United Kingdom that took part in the survey (England, Northern Ireland and Scotland). In Finland, Germany and Ireland, one surveillance system was limited to (legally required) public health notification of CDI cases, whereas additional systems collected laboratory-based data and enhanced epidemiological data on a voluntary basis. Public health notification of CDI was also carried out in Austria, Denmark and Hungary.

In Austria, France and Germany-2, surveillance of CDI targeted severe cases only. All surveillance systems included CDI in hospitalised patients, but 10/18 systems also included patients with community-acquired CDI. CDI case ascertainment was case-based (including clinical evaluation) in 7/18 systems, laboratory-based (relying on positive test results for toxin-producing $C$. difficile) in 5/18 systems or a combination of both in an additional 5/18 surveillance systems. Only Finland-3 used the International Statistical Classification of Diseases 10th revision (ICD-10)-based discharge coding [13] to find cases of CDI.

\section{Definitions of $C$. difficile infection}

The definitions used for CDI surveillance are summarised in the Box .

The majority $(12 / 18)$ of the surveillance systems used the ECDC and CDC case definition of CDI [2,14], 4/18 used other definitions and 2/18 did not use a specific case definition (but relied instead on the diagnosis of the attending physician and a positive laboratory test result for toxigenic $C$. difficile). More detailed definitions for community-associated CDI, community-onset of healthcare-associated CDI and healthcare-onset of healthcare-associated CDI were used by 9/18 (ECDC definition: 7/9, other definitions: 2/9). Definitions differing from ECDC's for community-associated CDI, community-onset healthcare-associated CDI and healthcare-onset healthcare-associated CDI used a time point of $\geq 72$ hours or $>3$ days (i.e. on or after day 4 of admission) instead of $\geq 48$ hours between admission and onset of symptoms to distinguish between community- and healthcare-associated CDI.

In $13 / 18$ surveillance systems, there was a definition for severe cases of CDI (ECDC definition: 5/13, other definitions: $8 / 13$ ) and in 11/18 systems, there was also a definition for recurrence of CDI (ECDC definition: 9/11, other definitions: 2/11). Definitions differing from ECDC's definition for severe/complicated course of CDI used additional criteria such as bloody diarrhoea, temperature $>38.5^{\circ} \mathrm{C}$, white cell count $>15 \times 109 / \mathrm{L}$, decreased kidney function or hypo-albuminaemia ( $<30$ 
Definitions, including surveillance system-specific definitions ${ }^{\mathrm{a}}$, for surveillance of Clostridium difficile infections

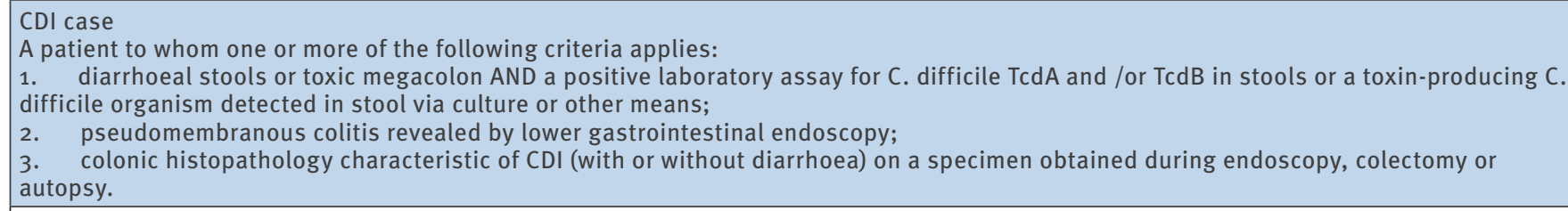

Differing definitions:

Finland-1: Detection of $C$. difficile organism/DNA/RNA/toxin in a clinical sample.

Finland-3: International Classification of Diseases (ICD)-10 codes A04.7 and $\mathrm{K}_{52.8}$ specific for Clostridium difficile-associated disease.

UK-England: Diagnoses on the basis of tests for C. difficile toxins A and B on diarrhoeal stool samples. Positive results on the same patient within 28 days of the first specimen are regarded as a single episode. All cases are reported regardless of location of the patient at the time the specimen was taken, i.e. regardless of whether the patient was in a hospital or another setting. Diarrhoeal stools are defined as 'those that take the shape of their container'. One (unexplained) diarrhoeal episode is sufficient to qualify for a diagnosis of CDI if the laboratory test is supportive.

UK-Northern Ireland: A patient aged two years and over from whom a diarrhoeal specimen is tested positive for C. difficile.

Community-associated CDI

Onset of CDI outside a healthcare facility (HCF) or within 48 hours following admission to a healthcare facility without residence in/ discharge from a healthcare facility within the previous 12 weeks.

Differing definitions:

Finland-2 and Germany-1: Onset of CDI in an outpatient or inpatient within 72 hours after admission to the facility.

Community-onset of healthcare-associated CDI

Onset of CDI in the community within 4 weeks following discharge from a healthcare facility.

Healthcare-onset of healthcare-associated CDI

Onset of CDI at least 48 hours (> 48 hours) following admission to a healthcare facility

Complicated course of CDI ( severe CDI case)

A patient to whom any of the following criteria applies:

1. admission to a healthcare facility for treatment of community-associated CDI;

2. admission to an intensive-care unit for treatment of CDI or its complication (e.g. for shock requiring vasopressor therapy);

3. surgery (colectomy) for toxic megacolon, perforation or refractory colitis;

4. death within 30 days after diagnosis, if CDI is either the primary or a contributive cause.

Differing definitions:

Austria: CDI requiring admission to an intensive-care unit/CDI requiring surgery/fatal cases of CDI.

Germany: Instead of 1: Readmission because of recurrent CDI (points 2-4 as above)

France: In addition: white cell count $>20 \times 103 / \mathrm{mm} 3$.

Hungary: Death linked to CDI (based on death register).

Ireland-2: 1. Admission to an intensive care unit for treatment of CDI or its complication (e.g. for shock requiring vasopressor therapy) and/

or 2. surgery (colectomy) for toxic megacolon, perforation or refractory colitis.

The Netherlands: 1 . Bloody diarrhoea and/or 2. pseudomembranous colitis and/or 3. diarrhoea in combination with dehydration and/or

hypo-albuminaemia ( $330 \mathrm{~g} / \mathrm{L}) 4$. temperature $>38^{\circ} \mathrm{C}$ and white cell count $>15 \times 109 / \mathrm{L}$.

UK-England: Temperature $>38.5^{\circ} \mathrm{C}$, white cell count $>15 \times 109 / \mathrm{L}$, decreased kidney function, or evidence of colitis.

UK-Scotland: In addition: Endoscopic diagnosis of pseudomembranous colitis (with or without toxin confirmation) persisting CDI where the patient has remained symptomatic and toxin positive despite two courses of appropriate therapy.

Recurrent CDI

An episode of CDI that occurs $>2$ weeks and $\leq 8$ weeks following the onset of a previous episode.

Differing definitions:

UK-England: A positive specimen taken more than 28 days after the initial specimen is considered a new CDI episode.

UK-Scotland: A new episode is defined as one occurring more than 28 days after the previous onset.

CDI: Clostridium difficile infection; UK: United Kingdom.

a Some countries had more than one surveillance system in parallel.

Source: $[2,14]$. Surveillance system-specific definitions: this study.

g/L). Definitions differing from those used by ECDC for recurrent $C D I$ used a time lapse of between two and four weeks after the previous onset to distinguish between different episodes of CDI.

\section{Collection of $C$. difficile infection surveillance data}

In 5/18 surveillance systems, data collection was done only by laboratories, in 7/18 only by infection control teams, and in $5 / 18$ by both. One surveillance system used hospital administration data only (Finland-3). In $8 / 18$ surveillance systems, case-based data were collected by healthcare personnel (in $7 / 8$ in combination with the infection control teams). In addition, general practitioners were engaged in surveillance data collection in Austria and UK-Scotland, as were public health doctors in Ireland-1. Only 3/18 surveillance systems relied solely on laboratory tests positive for CDI without additional patient data (Denmark, Finland-1, Sweden).

The collected data were pooled nationwide in 11/18 surveillance systems (Belgium, Bulgaria Finland-1, Finland-3, France, Hungary, Ireland-1, Ireland-2, 
Sweden, UK-Northern Ireland and UK-Scotland), per district or health board in 9/18 systems (Austria, Denmark, Finland-1, Finland-3, France, Germany-2, Ireland-1, UK-Northern Ireland and UK-Scotland), per healthcare facility in 9/18 systems (Belgium, Bulgaria, Finland-2, France, Germany-1, Ireland-2, the Netherlands, UK-England, UK-Northern Ireland) and per unit within a healthcare facility in $2 / 18$ systems (Finland-2, UK-Northern Ireland). In Finland-3 and Sweden, the collected data were also pooled per laboratory. Data about the size or type of the reporting healthcare facility were collected in 12/18 CDI surveillance systems, but not in the remaining six systems (Austria, Denmark, Finland-1, Germany-2, Hungary, Sweden). In 8/18 surveillance systems, even the speciality of the reporting unit or department was known. Most of the surveillance systems collected patient data: age and sex of CDI cases were reported in 16/18 surveillance systems, the date of onset of CDI in 13/18 systems and the date of admission in 11/18 systems. Only one surveillance system did not collect any patient data (Germany-1). Data about the history of CDI cases were collected in 6/18 surveillance systems (number of previous hospital admissions: $2 / 6$, number of previous episodes of CDI: 4/6; recurrent CDI: 5/6) and data about the outcome of CDI (death within 30 days) were collected in $5 / 18$ systems.

\section{Reporting of C. difficile infection surveillance data}

CDI surveillance results were periodically reported in $16 / 18$ surveillance systems (ranging from daily reports in UK-Northern Ireland to annual reports in 9/18 systems); only $2 / 18$ surveillance systems did not report the results at regular intervals (Finland-3, Germany-2). All 18 surveillance systems published their reports nationally, but in $6 / 18$ and $3 / 18$ surveillance systems, there were additional regional and local reports, respectively. Most $(12 / 18)$ of these reports were available to the public and healthcare professionals; only $4 / 18$ and $2 / 18$ surveillance systems published reports that solely targeted healthcare professionals or the public, respectively. Surveillance results were stratified in $8 / 18$ surveillance systems, mostly by geographical region (4/8) or type of healthcare facility $(4 / 8)$. More details, including denominators and calculated CDI rates, are given in the Table.

\section{Typing}

Typing of $C$. difficile was performed by national reference laboratories in 13 European countries with CDI surveillance, PCR ribotyping (either agarose: $8 / 13$, acrylamide: $1 / 13$ or capillary gel-based: 4/13) being the preferred method. Only one reference laboratory also used tcdC typing (Belgium). For the purposes of surveillance, typing was done in 13/18 European surveillance systems with varying criteria for submitting strains for further typing: severe CDI (9/13), outbreaks (7/13), isolates resistant to moxifloxacin (Denmark) or a more systematic sampling design selecting (4/13), e.g. the first five strains of each semester, i.e. each half of the year (Belgium), all strains of selected calendar periods (Sweden, UK-Scotland) or selected hospitals (the Netherlands). An overview is given in the Table. A more detailed analysis was performed by another ECDISNet survey in 2011 and 2014 of diagnostic and typing capacity for CDI in Europe: the results of which are also reported in this issue [15].

\section{Susceptibility testing}

There were no official recommendations for routine susceptibility testing of $C$. difficile isolates in any of the European countries taking part in ECDIS-Net, but susceptibility testing results were included in 7/18 CDI surveillance systems analysed. Conditions leading to susceptibility testing were the surveillance of antimicrobial resistance itself $(5 / 7)$, severe CDI cases $(4 / 7)$ or outbreaks of CDI (3/7).

\section{Discussion}

This survey showed that 14 of 31 European countries surveyed conducted some kind of CDI surveillance in 2011. The majority of the 18 existing European nationwide CDI surveillance systems were continuous and prospective, and captured CDI cases by standardised case definitions targeting the clinical symptoms of CDI and/or laboratory diagnosis of CDI, and all of them included CDI in hospitalised patients. However, there were interesting differences between these systems. In $11 / 18$ of European countries with CDI surveillance, surveillance was mandatory, either by mandatory reporting of laboratory and/or clinically confirmed cases or by public health notification of CDI. Whether surveillance should be based on mandatory or voluntary reporting of confirmed cases is still under discussion [16-18]. Opponents of mandatory reporting argue that especially in combination with public reporting of surveillance results and financial penalties, it may lead to systematic under-reporting of cases.

An important issue for surveillance purposes is the definition of CDI cases. These definitions should be valid, specific, easily understood, generally applicable and meet the requirements of different clinical settings, ideally across borders. Moreover, they should allow the comparison of local, regional, national and international infection rates [19]. The definitions proposed by the study group for $C$. difficile of the European Society of Clinical Microbiology and Infectious Diseases (ESCMID) and ECDC [2] are in agreement with those of the United States Centers for Disease Control and Prevention (CDC) $[2,14]$. Most of the European CDI surveillance systems adhere to these definitions, but difficulties are encountered in differentiating between community- and healthcare-associated cases of CDI. Some surveillance systems do not make any distinction between the two types of cases (for instance, when only laboratory data are used), while others use different time points for differentiating between the two. Stratification of community-associated and healthcare-associated $C D I$ cases may permit recognition of changes in epidemiology, e.g. an increase in the 
number of community-associated cases of CDI possibly caused by 'hypervirulent' $C$. difficile strains $[1,20,21]$. For feasibility reasons, the definitions of communityand healthcare-associated cases of CDI could be simplified, e.g. by adjusting the threshold time between the two types of cases to three days or later instead of 48 hours. However, regardless of the threshold used, variable proportions of CDI cases defined as community-associated CDI cases may in fact be linked to recent hospitalisation.

In order to meet the ECDC CDI case definitions, most surveillance systems used laboratory reporting and identification of CDI cases by attending healthcare personnel and/or infection control practitioners; few relied solely on laboratory test results. Only one of the Finnish surveillance systems used ICD-10 coding of CDI supplied by hospital administrations. In comparison with surveillance using CDI case definitions, surveillance using ICD coding has shown to be less sensitive $[22,23]$. In Finland, three different surveillance systems for CDI are run in parallel and so may compensate for their respective limitations.

All surveillance systems reporting hospital-associated CDI cases express CDI rates as incidence rate (per number of patient admissions within a given surveillance period) or incidence density (per number of patientdays). However, different orders of magnitude are used (100 or 1,000 admissions and 1,000 or 10,000 patientdays). Apart from that, surveillance systems only reporting the total number (i.e. community-associated and hospital-associated combined) of CDI cases mostly calculate the incidence per number of inhabitants; only a few exceptions just give the cumulative number of CDI cases. According to published recommendations and for better comparison, the incidence density of healthcare-associated and community-associated CDI should be expressed per 10,000 patient-days and 100,000 inhabitants, respectively $[14,19]$.

More than half of the European CDI surveillance systems presented their findings pooled, i.e. without any further stratification. Unfortunately, only a few surveillance systems provided sender-specific analyses. This would, however, be very important to inform interventions at local level and may help to reduce infection rates $[24]$.

Microbiological data may be an important supplement to epidemiological surveillance data and allow deeper insights into epidemiological changes. In our survey, however, strain typing and susceptibility testing were mainly restricted to outbreaks of CDI or severe cases of CDI; only a few surveillance protocols included typing or susceptibility testing on a regular basis. Although lacking the discriminatory power to study outbreaks, $P C R$ ribotyping is the most adopted $C$. difficile typing methodology in European reference laboratories. International standardisation of ribotyping methods would allow comparability and reproducibility between countries. Capillary-based ribotyping offers the opportunity to achieve these aims, as results are easier to interpret and to exchange than those of conventional agarose-based ribotyping [25-27].

The main limitations of microbiological testing for $C$. difficile are financial, and shipment of strains to reference laboratories for typing may be hampered by the fact that many laboratories perform toxin testing alone and do not culture $C$. difficile.

Published recommendations of ECDC and the United States Centers for Disease Control and Prevention (CDC) are that CDI surveillance should be conducted for at least all inpatients to monitor healthcare-associated CDI, and healthcare-associated CDI rates should be expressed as number of cases per 10,000 patient-days $[2,14]$. A standardised European CDI surveillance protocol should be used to allow meaningful intercountry comparisons of CDI incidence rates and for follow-up of the epidemiology of CDI at European level. Special emphasis should be given to the harmonisation of definitions of community-associated and healthcareassociated CDI, inclusion criteria for patients and CDI cases, criteria for typing $C$. difficile strains, denominator data, epidemiological case-based data and casefinding methods. In order to integrate microbiological test results into CDI surveillance, more frequent culture of $C$. difficile is required, and typing methods should be standardised. Harmonised systematic surveillance at national and European level is more likely to facilitate the identification of epidemiological changes and the optimal control of CDI. As a result of this survey, ECDC published a harmonised EU/EEA-wide hospitalbased CDI surveillance protocol in May 2015 [12].

Members of ECDIS-Net (national coordinators)

Austria: F. Allerberger, AGES - Institut für medizinische Mikrobiologie und Hygiene, Wien; Belgium: M. Delmée, University of Louvain, Brussels; Bulgaria: K. Ivanova, R. Vatcheva-Dobrevska, National Centre for Infectious and Parasitic Diseases, Sofia; Croatia: B. Matica, Public Health Institute $\operatorname{Dr}$ A. Štampar, Zagreb; Cyprus: P. MaikantiCharalampous, Nicosia General Hospital, Nicosia; Czech Republic: O. Nyč, Hospital FN Motol Prague, Prague; Denmark: K.E.P. Olsen, Statens Serum Institut, Copenhagen; Estonia: M. Jyrna-Ellam, North Estonia Medical Centre, Tallinn; Finland: O. Lyytikäinen, S. Mentula, A. Virolainen, THL (National Institute for Health and Welfare), Helsinki; France: F. Barbut, Hôpital Saint-Antoine, Paris; B. Coignard, C. Eckert, Institut de Veille Sanitaire, Saint-Maurice Cedex; Germany: T. Eckmanns, Robert Koch-Institut, Berlin; L. von Müller; University of Saarland Medical Centre, Homburg Greece: E. Malamou-Lada, M. Orfanidou, G. Gennimatas General Hospital, Athens; Hungary: E. Nagy, Faculty of Medicine, University of Szeged, Szeged; Ireland: F. Fitzpatrick, Health Protection Surveillance Centre, Dublin; Italy: P. Mastrantonio, Istituto Superiore di Sanità, Rome; Latvia: A. Balode, Pauls Stradins Cilincal University hospital, Riga; Liechtenstein: M. Ritzler, Labormedizinisches Zentrum Dr. Risch, Schaan; Lithuania: J. Miciuleviciene, National Public Health Surveillance Laboratory, Vilnius; Luxembourg: M. Perrin, Laboratoire National de Santé (LNS), Luxembourg; Netherlands: B. van Benthem and D. Notermans, Center for 
Infectious Disease Control, Bilthoven; E.J. Kuijper, Leiden University Medical Centre, Leiden; Norway: A. Ingrebretsen, Rikshospitalet University Hospital, Oslo; Poland: H. Pituch, Medical University of Warsaw, Warsaw; Portugal: M.A. Sousa Oleastro, Departamento de Doenças Infecciosas Instituto Nacional de Saúde Dr Ricardo Jorge, Lisboa; Romania: D. Lemeni, Cantacuzino Institute, Bucarest; Slovakia: K. Kramarova, E. Novakova, Comenius University, Jessenius Faculty of Medicine, Martin; Slovenia: M. Rupnik, Institute of Public Health, Maribor, J. Kolman, National Institute of Public Health, Ljubljana; Spain: E. Bouza, M. Marin, L. Alcala, Hospital General Universitario Gregorio Marañón, Madrid; Sweden: T. Åkerlund, O. Aspevall, Public Health Agency of Sweden, Solna; Switzerland: A.F. Widmer, S. Erb, University Hospital, Basel; Turkey: B. Levent, Refik Saydam National Public Health Agency, Ankara; United Kingdom - England: M. Wilcox, Leeds Teaching Hospitals NHS Trust, Leeds; United Kingdom - Northern Ireland: P. Rooney, Belfast City Hospital, Belfast; United Kingdom - Scotland: C. Wiuff, Health Protection Scotland, Glasgow, J. Coia, Scottish Microbiology Reference Laboratories, Glagow.

\section{Acknowledgements}

Funding: the survey was part of the ECDIS-Net project initiated and funded by the European Centre for Disease Prevention and Control (ECDC) through a specific service contract $(E C D C / 10 / 022)$ to the University Medical Center, Leiden, the Netherlands.

We acknowledge Alexander Gropmann for development and support of the web-based questionnaire.

\section{Conflict of interest}

Mark H Wilcox: received research work fees, and/or consulting fees and/or lecture fees from Actelion, Cubist, Astellas, Merck, Optimer, Sanofi-Pasteur, Summit, Astra-Zeneca, Cerexa, Nabriva, Novacta, Novartis, Pfizer, Corporation Roche, The Medicines Company, VH Squared, Abbott, bioMerieux, Da Volterra, European Tissue Symposium, Basilea, and Alere (paid to the department), and a clinical trial consultancy from Durata.

Ed J Kuijper: participated in advisory forums of Actelion, Astellas, Merck, Pfizer, Sanofi-Pasteur, Seres and Summit, and received unrestricted grant supports from Actelion, Merck, Becton-Dickenson and Cubist.

All other authors: none declared.

\section{Authors' contributions}

The survey was designed by AK, DWK and PG, with support of $B H B, B C, O L$, JS and CW. EJK and MHW were the principle coordinators of ECDIS-Net, using support of CS from ECDC. $A K$ and DWK performed data collection and data analysis, PG supervised data collection and data analysis. AK wrote the manuscript together with $\mathrm{CW}$. All co-authors reviewed the manuscript.

\section{References}

1. Freeman J, Bauer MP, Baines SD, Corver J, Fawley WN, Goorhuis $B$, et al. The changing epidemiology of Clostridium difficile infections. Clin Microbiol Rev. 2010;23(3):529-49. DOI: 10.1128/ CMR.00082-09 PMID: 20610822

2. Kuijper EJ, Coignard B, Tüll P, ESCMID Study Group for Clostridium difficile, EU Member States, European Centre for Disease Prevention and Control. Emergence of Clostridium difficile-associated disease in North America and Europe.Clin
Microbiol Infect. 2006;12(Suppl 6):2-18. DOI: 10.1111/j.14690691.2006.01580.x PMID: 16965399

3. Honda H, Dubberke ER. The changing epidemiology of Clostridium difficile infection.Curr Opin Gastroenterol. 2014;30(1):54-62. DOI: 10.1097/MOG.0000000000000018 PMID: 24285002

4. Goorhuis A, Bakker D, Corver J, Debast SB, Harmanus C, Notermans DW, et al. Emergence of Clostridium difficile infection due to a new hypervirulent strain, polymerase chain reaction ribotype 078. Clin Infect Dis. 2008;47(9):1162-70. DOI: 10.1086/592257 PMID: 18808358

5. Goorhuis A, Debast SB, van Leengoed LA, Harmanus C, Notermans DW, Bergwerff AA, et al. Clostridium difficile PCR ribotype 078: an emerging strain in humans and in pigs? J Clin Microbiol. 2008;46(3):1157-8, author reply 1158. DOI: 10.1128/ JCM.01536-07 PMID: 18326836

6. Chernak E, Johnson CC, Weltman A, McDonald LC, Wiggs L, Killgore G, et al., Centers for Disease Control and Prevention (CDC). Severe Clostridium difficile-associated disease in populations previously at low risk--four states, 2005.MMWR Morb Mortal Wkly Rep. 2005;54(47):1201-5.PMID: 16319813

7. Wilcox MH, Mooney L, Bendall R, Settle CD, Fawley WN. A casecontrol study of community-associated Clostridium difficile infection.J Antimicrob Chemother. 2008;62(2):388-96. DOI: 10.1093/jac/dkn163 PMID: 18434341

8. Bauer MP, Goorhuis A, Koster T, Numan-Ruberg SC, Hagen EC, Debast SB, et al. Community-onset Clostridium difficileassociated diarrhoea not associated with antibiotic usage-two case reports with review of the changing epidemiology of Clostridium difficile-associated diarrhoea. Neth J Med. 2008;66(5):207-11.PMID: 18490799

9. Bauer MP, Notermans DW, van Benthem BH, Brazier JS, Wilcox MH, Rupnik M, et al. , ECDIS Study Group. Clostridium difficile infection in Europe: a hospital-based survey.Lancet. 2011;377(9759):63-73. DOI: 10.1016/S0140-6736(10)61266-4 PMID: 21084111

10. Barbut F, Mastrantonio P, Delmée M, Brazier J, Kuijper E, Poxton I, European Study Group on Clostridium difficile (ESGCD). Prospective study of Clostridium difficile infections in Europe with phenotypic and genotypic characterisation of the isolates.Clin Microbiol Infect. 2007;13(11):1048-57. DOI: 10.1111/j.1469-0691.2007.01824.x PMID: 17850341

11. van Dorp SM, Kinross P, Gastmeier P, Behnke M, Kola A, Delmée $M$, et al. Standardised surveillance of Clostridium difficile infection in European acute care hospitals: pilot study, 2013. Euro Surveill. 2016;21(29):30293. DOI: 10.2807/1560-7917.ES.2016.21.29.30293

12. European Centre for Disease Prevention and Control (ECDC). European Surveillance of Clostridium difficile infections. Surveillance protocol version 2.2. Stockholm: ECDC; 2015. Available from: http://ecdc.europa.eu/en/ publications/_layouts/forms/Publication_DispForm. aspx?List $=4$ f55ad51-4aed-4d32-b960-af70113dbb90\&ID=1402

13. World Health Organization (WHO). International Statistical Classification of Diseases and Related Health Problems 10th Revision (ICD-10). Geneva: WHO; 2010.

14. McDonald LC, Coignard B, Dubberke E, Song X, Horan T, Kutty PK, Ad Hoc Clostridium difficile Surveillance Working Group. Recommendations for surveillance of Clostridium difficile-associated disease.Infect Control Hosp Epidemiol. 2007;28(2):140-5. DOI: 10.1086/511798 PMID: 17265394

15. van Dorp SM, Notermans DW, Alblas J, Gastmeier P, Mentula $\mathrm{S}$, Nagy E, et al. Survey of diagnostic and typing capacity for Clostridium difficile infection in Europe, 2011 and 2014. Euro Surveill. 2016;21(29):30292. DOI: 10.2807/1560-7917. ES.2016.21.29.30292

16. Goldenberg SD, Price NM, Tucker D, Wade P, French GL. Mandatory reporting and improvements in diagnosing Clostridium difficile infection: an incompatible dichotomy?] Infect. 2011;62(5):363-70. DOI: 10.1016/j.jinf.2011.03.007 PMID: 21439999

17. Fridkin SK, Olmsted RN. Meaningful measure of performance: a foundation built on valid, reproducible findings from surveillance of health care-associated infections. Am J Infect Control. 2011;39(2):87-90. DOI: 10.1016/j.ajic.2011.01.002 PMID: 21356430

18. McKibben L, Fowler G, Horan T, Brennan PJ. Ensuring rational public reporting systems for health care-associated infections: systematic literature review and evaluation recommendations. Am J Infect Control. 2006;34(3):142-9. DOI: 10.1016/j. ajic.2005.09.006 PMID: 16630978

19. Cohen SH, Gerding DN, Johnson S, Kelly CP, Loo VG, McDonald LC, et al. , Society for Healthcare Epidemiology of America, Infectious Diseases Society of America. Clinical practice guidelines for Clostridium difficile infection in adults: 2010 update by the society for healthcare epidemiology of America 
(SHEA) and the infectious diseases society of America (IDSA). Infect Control Hosp Epidemiol. 2010;31(5):431-55. DOI: 10.1086/651706 PMID: 20307191

20. McDonald LC, Killgore GE, Thompson A, Owens RC, Kazakova SV, Sambol SP, et al. An epidemic, toxin gene-variant strain of Clostridium difficile. N Engl J Med. 2005;353(23):2433-41. DOI: 10.1056/NEJMoa051590 PMID: 16322603

21. Warny M, Pepin J, Fang A, Killgore G, Thompson A, Brazier J, et al. Toxin production by an emerging strain of Clostridium difficile associated with outbreaks of severe disease in North America and Europe. Lancet. 2005;366(9491):1079-84. DOI: 10.1016/S0140-6736(05)67420-X PMID: 16182895

22. Dubberke ER, Butler AM, Yokoe DS, Mayer J, Hota B, Mangino $\mathrm{JE}$, et al., Prevention Epicenters Program of the Centers for Disease Control and Prevention. Multicenter study of surveillance for hospital-onset Clostridium difficile infection by the use of ICD-9-CM diagnosis codes. Infect Control Hosp Epidemiol. 2010;31(3):262-8. DOI: 10.1086/650447 PMID: 20100085

23. Dubberke ER, Butler AM, Nyazee HA, Reske KA, Yokoe DS, Mayer J, et al. , Centers for Disease Control and Prevention Epicenters Program. The impact of ICD-9-CM code rank order on the estimated prevalence of Clostridium difficile infections. Clin Infect Dis. 2011;53(1):20-5. DOI: 10.1093/cid/cir246 PMID: 21653298

24. Gastmeier P, Sohr D, Schwab F, Behnke M, Zuschneid I, Brandt $C$, et al. Ten years of KISS: the most important requirements for success. J Hosp Infect. 2008;70(Suppl 1):11-6. DOI: 10.1016/ S0195-6701(08)60005-5 PMID: 18994676

25. Indra A, Huhulescu S, Schneeweis M, Hasenberger $P$, Kernbichler S, Fiedler A, et al. Characterization of Clostridium difficile isolates using capillary gel electrophoresis-based PCR ribotyping. J Med Microbiol. 2008;57(Pt 11):1377-82. DOI: 10.1099/jmm.0.47714-o PMID: 18927415

26. Fawley WN, Knetsch CW, MacCannell DR, Harmanus C, Du $\mathrm{T}$, Mulvey MR, et al. Development and validation of an internationally-standardized, high-resolution capillary gelbased electrophoresis PCR-ribotyping protocol for Clostridium difficile. PLoS One. 2015;10(2):e0118150. DOI: 10.1371/journal. pone.0118150 PMID: 25679978

27. Knetsch CW, Lawley TD, Hensgens MP, Corver J, Wilcox MW, Kuijper EJ. Current application and future perspectives of molecular typing methods to study Clostridium difficile infections. Euro Surveill. 2013;18(4):20381.PMID: 23369393

\section{License and copyright}

This is an open-access article distributed under the terms of the Creative Commons Attribution (CC BY 4.0) Licence. You may share and adapt the material, but must give appropriate credit to the source, provide a link to the licence, and indicate if changes were made.

This article is copyright of the authors, 2016. 